\title{
Is the GABA System Related to the Social Competence Improvement Effect of Aripiprazole? An ${ }^{18}$ F-Fluoroflumazenil PET Study
}

\author{
Jung Suk Lee 1,2 , Jong Doo Lee ${ }^{3}$, Hae-Jeong Park ${ }^{1,3}$, Maeng-Keun $\mathrm{Oh}^{3}$, \\ Ji Won Chun ${ }^{1,3}$, Se-Joo Kim ${ }^{1,4}$, Eosu Kim ${ }^{1,4}$ and Jae-Jin Kim ${ }^{1,4} \bowtie$ \\ ${ }^{1}$ Institute of Behavioral Science in Medicine, Yonsei University College of Medicine, Seoul, Republic of Korea \\ ${ }^{2}$ Department of Psychiatry, Bundang Jesaeng Hospital, Seongnam, Republic of Korea \\ ${ }^{3}$ Department of Nuclear Medicine, Yonsei University College of Medicine, Seoul, Republic of Korea \\ ${ }^{4}$ Department of Psychiatry, Yonsei University College of Medicine, Seoul, Republic of Korea
}

\begin{abstract}
Objective Patients with schizophrenia who are treated with aripiprazole experience some benefits including an improvement of social competence, but the underlying mechanism of this improvement has not been investigated yet. This study aimed to provide preliminary evidence that the GABA system may be involved in the effect of aripiprazole on social competence.

Methods Seventeen outpatients with schizophrenia ( 9 taking aripiprazole and 8 taking risperidone) and 18 healthy controls underwent ${ }^{18} \mathrm{~F}$-fluoroflumazenil PET, and $\mathrm{GABA}_{\mathrm{A}}$ receptor binding potential was compared between the three groups.

Results Voxelwise one-way ANOVA showed that $\mathrm{GABA}_{\mathrm{A}}$ receptor binding potentials in the right medial prefrontal cortex ( $\left.\mathrm{p}=0.04\right)$ and right dorsolateral prefrontal cortex $(\mathrm{p}=0.02)$ were significantly lower in the aripiprazole group than the risperidone group, and those in the left frontopolar cortex $(\mathrm{p}=0.03)$ and right premotor cortex $(\mathrm{p}=0.02)$ were significantly lower in the aripiprazole group than the risperidone and control groups.

Conclusion Our results suggest that aripiprazole administration results in increased GABA transmission in the prefrontal regions, and that these increases may be a neural basis of aripiprazole's clinical benefits on an improvement of social competence.
\end{abstract}

Psychiatry Investig 2013;10:75-80

Key Words $\mathrm{GABA}_{\mathrm{A}}$ receptor, Flumazenil PET, Aripiprazole, Social competence, Prefrontal cortex.

\section{INTRODUCTION}

Aripiprazole, a relatively new atypical antipsychotic, shares some advantages with other atypical antipsychotics, i.e., effectiveness on both positive and negative symptoms of schizophrenia. Moreover, some studies have shown additional benefits for aripiprazole, despite a controversy about the specificity of the benefits. For example, aripiprazole has a better efficacy in reducing deficit symptoms compared to other antipsycho-

Received: May 11, 2012 Revised: July 24, 2012

Accepted: August 3, 2012 Available online: January 24, 2013

$\triangle$ Correspondence: Jae-Jin Kim, MD, PhD

Department of Psychiatry, Yonsei University College of Medicine, Gangnam Severance Hospital, 211 Eonju-ro, Gangnam-gu, Seoul 135-720, Republic of Korea

Tel: +82-2-2019-3341, Fax: +82-2-3462-4304, E-mail: jaejkim@yonsei.ac.kr

(a) This is an Open Access article distributed under the terms of the Creative Commons Attribution Non-Commercial License (http://creativecommons.org/licenses/by$\mathrm{nc} / 3.0$ ) which permits unrestricted non-commercial use, distribution, and reproduction in any medium, provided the original work is properly cited. tics such as olanzapine, quetiapine or risperidone. ${ }^{1}$ Patients who switched from either olanzapine or risperidone to aripiprazole manifested improvements in subjective well-being. ${ }^{2}$ Our research group demonstrated that the usefulness of aripiprazole in patients with schizophrenia included the improvement of social competence, ${ }^{3}$ which refers to overall capacity to solve life problems and achieve instrumental and affiliative goals. ${ }^{4}$ These advantages of aripiprazole may be related to its distinctive pharmacological profile as a partial agonist of $\mathrm{D}_{2}$ and $\mathrm{HT}_{1 \mathrm{~A}}$ receptors and as an antagonist of 5- $\mathrm{HT}_{2 \mathrm{~A}}$ and $5-\mathrm{HT}_{2 \mathrm{C}}$ receptors. ${ }^{5}$ This profile of aripiprazole is contrasted with those of other atypical antipsychotics; for example risperidone acts as a potent antagonist of both $5-\mathrm{HT}_{2 \mathrm{~A}}$ and $\mathrm{D}_{2}$ receptors. ${ }^{6}$ Although the relationship between aripiprazole and $\gamma$-aminobutyric-acid (GABA) is not studied yet, the GABAergic mechanism may be also involved in the advantages of aripiprazole in that GABAergic neurotransmission closely interacts 
with the dopamine and serotonin systems. ${ }^{7}$

In fact, dysfunctional GABA transmission in the brain has been considered to play a role in the pathophysiology of schizophrenia. For example, postmortem studies have reported upregulation of GABA receptor binding in the prefrontal cortex of patients with schizophrenia, whereas in vivo neuroimaging studies using SPECT and $\left[{ }^{11} \mathrm{C}\right]$ Ro15-4513 PET have demonstrated that there is no difference in $\mathrm{GABA}_{\mathrm{A}}$ receptor binding between patients with schizophrenia and healthy controls. ${ }^{7}$ Moreover, the GABA system is believed to be related to the mechanism responsible for the efficacy of antipsychotic medications. ${ }^{8,9}$ A previous pharmacoimaging study ${ }^{9}$ reported that typical and atypical antipsychotics had a different effect on regional GABA activities, but grouped together all atypical antipsychotics in one category and thus ignored a different mechanism of action or efficacy among the drugs. To our knowledge, no studies have examined the difference of regional GABA receptor binding potential between patients taking atypical antipsychotics. Therefore, further study deserves to be performed to clarify the effect on the GABA system by each of atypical antipsychotics including aripiprazole.

It should be considered here that GABAergic inhibition modulates cortical signal transduction operative in information processing. ${ }^{7}$ If patients with schizophrenia who administer aripiprazole show a distinctive GABA-related change in some brain regions which are closely related to social functions, it can be considered to be a neural basis of aripiprazole's additional efficacy, especially on social competence. ${ }^{3}$ There are many brain structures that underlie social functions, which includes 1) prefrontal regions including the medial prefrontal cortex (MPFC), dorsolateral prefrontal cortex (DLPFC), frontopolar cortex (FPC), and premotor cortex, 2) temporoparietal regions including the temporal pole, superior temporal sulcus, temporoparietal junction and inferior parietal lobule, and 3) the amygdala. ${ }^{10-12}$ Taken together, we regarded these structures as the a priori regions in the present study for investigating changes in GABAergic neurotransmission by aripiprazole.

This study was designed to examine a difference in $\mathrm{GABA}_{\mathrm{A}}$ receptor binding potential between long-term use of aripiprazole and risperidone using $\left[{ }^{18} \mathrm{~F}\right]$-FFMZ PET imaging in regions which were related to social functions. We hypothesized that the $\mathrm{GABA}_{\mathrm{A}}$ receptor binding potentials in social competence-related brain regions would be changed in the aripiprazole group.

\section{METHODS}

\section{Subjects}

Seventeen patients with schizophrenia and 18 healthy controls participated in this study. Inclusion criteria were an ex- clusive diagnosis of schizophrenia in the patient group and the exclusion of any psychiatric disorder in the control group. Psychiatric diagnoses were assessed with the Structured Clinical Interview for DSM-IV. ${ }^{13}$ Clinical symptoms of schizophrenia in the patient group were assessed using the Positive and Negative Syndrome Scale (PANSS). ${ }^{14}$ No participants reported any past or present history of significant medical or neurological illness and drug or alcohol abuse. Patients and controls did not significantly differ in gender (eight males in the patient group, nine males in the control group), age ( $28.7 \pm 6.9$ years and $26.2 \pm 6.9$ years, respectively), or years of education (14.0 \pm 1.6 years and $13.7 \pm 1.5$ years, respectively). The study was approved by the institutional review board and written informed consent was obtained from all participants.

The patient group was divided into two subgroups according to antipsychotic medication. Nine patients were taking aripiprazole monotherapy (mean dose: $17.8 \pm 9.4 \mathrm{mg}$ ) and eight patients were taking risperidone monotherapy (mean dose: $3.4 \pm 2.4 \mathrm{mg}$ ). All patients and controls had not received benzodiazepines for at least four weeks prior to the PET imaging session, but other medications were not restricted; two patients in the aripiprazole group reported current use of antidepressants, six in the aripiprazole group and one in the risperidone group used propranolol, and six in the aripiprazole group and two in the risperidone group used anticholinergics. There was one left-handed patient in each subgroup. As shown in Table 1 , the aripiprazole, risperidone and control groups did not differ in gender, age and years of education. The two medication groups also did not differ in terms of duration of illness, duration of antipsychotics treatment, total and subscale scores of the PANSS, or mean chlorpromazine-equivalent dose of their antipsychotic medication.

\section{$\left[{ }^{18} \mathrm{~F}\right]$-FFMZ PET imaging}

To investigate $\mathrm{GABA}_{\mathrm{A}}$ receptor binding potential, all subjects were scanned using a GE Discovery STE PET/CT scanner (GE, Milwaukee, WI, USA). A 10 min transmission CT scan was performed for attenuation correction. After injection of approximately $5.5 \mathrm{MBq}(0.15 \mathrm{mCi}) / \mathrm{kg}$ of $\left[{ }^{18} \mathrm{~F}\right]$-FFMZ, a dynamic emission scan was performed in a sequence of 150 frames in 3 -D mode $(60 \times 10 \mathrm{~s}, 40 \times 15 \mathrm{~s}, 20 \times 30 \mathrm{~s}$ and $30 \times 60 \mathrm{~s})$ for a total acquisition time of $60 \mathrm{~min}$. As described in our previous study using $\left[{ }^{18} \mathrm{~F}\right]$-FFMZ, ${ }^{15}$ actual emission data for statistical analysis were obtained for $20 \mathrm{~min}$ in $20 \mathrm{~min}$ after injection of the radiotracer to avoid blood flow effects and nonspecific $\mathrm{GABA}_{\mathrm{A}}$ receptor binding. The attenuation-corrected emission data were reconstructed in a $128 \times 128 \times 47$ matrix with a pixel size of $2.34 \times 2.34 \times 3.27 \mathrm{~mm}$ using Hanning and Ramp filters. 
Table 1. Comparison of clinical and demographic characteristics between the aripiprazole and risperidone groups

\begin{tabular}{|c|c|c|c|c|c|}
\hline & Aripiprazole group $(\mathrm{N}=9)$ & Risperidone group $(\mathrm{N}=8)$ & Control group $(\mathrm{N}=18)$ & $F / T / \chi^{2}$ & $\mathrm{p}$ \\
\hline Age (years) & $27.3 \pm 5.0$ & $30.1 \pm 8.7$ & $26.2 \pm 6.9$ & 0.88 & 0.43 \\
\hline Education (years) & $13.9 \pm 1.8$ & $14.1 \pm 1.6$ & $13.7 \pm 1.5$ & 0.25 & 0.79 \\
\hline Gender $(\mathrm{M} / \mathrm{F})$ & $3 / 6$ & $5 / 3$ & $9 / 9$ & $1.47^{*}$ & 0.48 \\
\hline Handedness (R/L) & $8 / 1$ & $7 / 1$ & $18 / 0$ & $2.26^{*}$ & 0.32 \\
\hline $\begin{array}{l}\text { Dose of antipsychotics } \\
\text { (CP equivalence) }\end{array}$ & $236.9 \pm 125.4$ & $168.8 \pm 122.3$ & - & 1.13 & 0.28 \\
\hline Duration of illness (years) & $4.8 \pm 3.0$ & $3.4 \pm 1.8$ & - & 1.15 & 0.27 \\
\hline Duration of treatment (years) $^{\dagger}$ & $1.9 \pm 1.0$ & $2.9 \pm 1.9$ & - & -1.30 & 0.21 \\
\hline \multicolumn{6}{|l|}{ PANSS } \\
\hline Positive & $15.8 \pm 4.3$ & $15.6 \pm 4.8$ & - & 0.07 & 0.95 \\
\hline Negative & $15.1 \pm 3.0$ & $13.5 \pm 3.8$ & - & 0.97 & 0.35 \\
\hline General & $29.0 \pm 5.5$ & $31.1 \pm 6.8$ & - & -0.71 & 0.49 \\
\hline Total & $61.0 \pm 9.5$ & $60.3 \pm 14.1$ & - & 0.13 & 0.90 \\
\hline
\end{tabular}

Values are presented as means $\underline{ \pm}$ standard deviation. ${ }^{*}$ Pearson's chi-square value, ${ }^{\dagger}$ duration of aripiprazole or risperidone was administered. CP: chlorpromazine, PANSS: Positive and Negative Syndrome Scale

\section{Image preprocessing}

Preprocessing and statistical analysis of $\left[{ }^{18} \mathrm{~F}\right]$-FFMZ PET images were performed using Statistical Parametric Mapping (SPM) software (SPM8, Institute of Neurology, University College London, UK). We first created a $\left[{ }^{18} \mathrm{~F}\right]$-FFMZ PET template using $\left[{ }^{18} \mathrm{~F}\right]$-FFMZ PET images and T1-weighted MR images of 20 healthy volunteers. ${ }^{15}$ All $\left[{ }^{18} \mathrm{~F}\right]$-FFMZ PET images obtained from patients and normal controls were spatially normalized into the $\left[{ }^{18} \mathrm{~F}\right]$-FFMZ PET template to remove inter-subject anatomical variability. To calculate the $\mathrm{GABA}_{\mathrm{A}}$ receptor binding potential, we used a multi-linear reference tissue method. ${ }^{16}$ Given that the density of $\mathrm{GABA}_{\mathrm{A}}$ receptors in the pons is negligible, effect of global uptake was taken into account by normalizing the count of each voxel to the mean count within the pons. The $\mathrm{GABA}_{\mathrm{A}}$ receptor binding potential images were then smoothed by convolution with an isotropic Gaussian kernel with a 14-mm.

\section{Statistical analysis}

A group comparison of $\mathrm{GABA}_{\mathrm{A}}$ receptor binding potentials between all patients and healthy controls was performed by voxel-wise $\mathrm{t}$-statistics at a threshold at uncorrected $\mathrm{p}<0.005$ with more than 20 contiguous voxels. A difference of $G_{A B A}$ receptor binding potentials among the aripiprazole, risperidone and control groups was evaluated by voxel-wise oneway analysis of variance (ANOVA). An exploratory analysis for screening activations in the a priori regions was done at a threshold of uncorrected $\mathrm{p}<0.01$ with more than 20 contiguous voxels, and then the significant clusters in the a priori regions were used for secondary small volume correction (SVC) analysis, which was conducted at family wise error $(\mathrm{FWE})^{17}$ - corrected $\mathrm{p}<0.05$ using $5-\mathrm{mm}$ sphere with a fixation point at the local maxima.

For post hoc analyses, the whole volumes of the clusters were defined as the regions of interest (ROIs), and the regional mean $\left[{ }^{18} \mathrm{~F}\right]$-FFMZ binding potentials of each subject were then tested for significance based on the ROIs using the individual $\left[{ }^{18} \mathrm{~F}\right]$-FFMZ binding potential maps. Independent $\mathrm{t}-$ tests for the ROI values were performed and Scheffés method was applied to correct for multiple comparisons.

\section{RESULTS}

As shown in Table 2, compared to the control group, $\left[{ }^{18} \mathrm{~F}\right]-$ FFMZ binding potential in the patient group was decreased in the subgenual cingulate cortex and left temporal pole, and increased in the right inferior occipital gyrus. As shown in Table 3 and Figure 1, a comparison of $\left[{ }^{18} \mathrm{~F}\right]$-FFMZ binding potential among the aripiprazole, risperidone and control groups revealed significant differences in 4 prefrontal regions including the right MPFC, left FPC, right DLPFC, and right premotor cortex. A significant cluster was not found in other a priori regions such as the temporoparietal regions and amygdala.

Post hoc analyses revealed that $\left[{ }^{18} \mathrm{~F}\right]$-FFMZ binding potentials in the right MPFC and the right DLPFC was significantly lower in the aripiprazole group than the risperidone group, but they were not significantly different between the risperidone and control groups, or between the aripiprazole and control groups. $\left[{ }^{18} \mathrm{~F}\right]$-FFMZ binding potentials in the left FPC and the right premotor cortex were significantly lower in the aripiprazole group than the risperidone and control groups. 


\section{DISCUSSION}

A comparison between the patient and control groups revealed that $\left[{ }^{18} \mathrm{~F}\right]$-FFMZ binding potentials in the medicated patients were increased in the right inferior occipital gyrus, and decreased in the subgenual cingulate cortex and the left temporal pole. Given that increased $\mathrm{GABA}_{\mathrm{A}}$ receptor is considered an effect of an upregulation of the $\mathrm{GABA}_{\mathrm{A}}$ receptor complex due to presynaptic GABAergic deficiencies, ${ }^{7}$ regional increases of $\mathrm{GABA}_{\mathrm{A}}$ receptor binding potential may indicate decreased GABA transmission. Therefore, decreased $G_{A B A_{A}}$ receptor binding potential may be interpreted as increased GABA transmission and decreased regional brain activity. Since the subgenual cingulate cortex and the temporal pole has been implicated in emotion regulation, ${ }^{18,19}$ decreased $\mathrm{GABA}_{\mathrm{A}}$ receptor binding potential in these regions may be related to emotional abnormality found in patients with schizophrenia. However, given that the patients in this study were medicated

Table 2. Decreased or increased $\mathrm{GABA}_{\mathrm{A}}$ receptor binding potential in the patient group when compared with the control group at a threshold of uncorrected $p<0.005$

\begin{tabular}{|c|c|c|c|c|c|}
\hline \multirow{2}{*}{ Regions } & \multirow{2}{*}{ Nvox } & \multirow{2}{*}{$Z \max$} & \multicolumn{3}{|c|}{ MNI coordinates } \\
\hline & & & $\mathrm{x}$ & $\mathrm{y}$ & $\mathrm{z}$ \\
\hline \multicolumn{6}{|l|}{ Decreases in the patient group } \\
\hline Subgenual cingulate cortex (BA25) & 106 & 2.90 & 2 & 8 & -4 \\
\hline Left temporal pole (BA38) & 23 & 2.75 & -46 & 18 & -12 \\
\hline \multicolumn{6}{|l|}{ Increases in the patient group } \\
\hline Right inferior occipital gyrus (BA19) & 80 & 2.76 & 38 & -74 & -4 \\
\hline
\end{tabular}

Nvox: number of voxels, Zmax: maximum Z value, MNI: Montreal Neurological Institute, BA: Brodmann area

Table 3. Comparison of $\mathrm{GABA}_{A}$ receptor binding potential among the aripiprazole (A), risperidone (R) and control (C) groups at a threshold of family wise error (FWE) corrected $p<0.05$

\begin{tabular}{lcccccc}
\hline \multicolumn{1}{c}{ Regions } & \multirow{2}{*}{ Nvox } & Zmax & \multicolumn{3}{c}{ MNI coordinates } & Post-hoc \\
\cline { 4 - 6 } & & & $\mathrm{x}$ & $\mathrm{y}$ & $\mathrm{z}$ & $\mathrm{A}<\mathrm{R}, \mathrm{A}=\mathrm{C}, \mathrm{R}=\mathrm{C}$ \\
Right medial prefrontal cortex (BA10) & 36 & 2.52 & 8 & 58 & 2 & $\mathrm{~A}=\mathrm{C}<\mathrm{R}$ \\
Left frontopolar cortex (BA10) & 32 & 2.52 & -22 & 58 & 14 & $\mathrm{~A}<\mathrm{R}, \mathrm{A}=\mathrm{C}, \mathrm{R}=\mathrm{C}$ \\
Right dorsolateral prefrontal cortex (BA46) & 29 & 2.68 & 36 & 44 & 8 & $\mathrm{~A}<\mathrm{C}=\mathrm{R}$ \\
Right premotor cortex (BA6) & 52 & 2.72 & 60 & 0 & 22 & \\
\hline
\end{tabular}

For post hoc analyses, the whole volumes of the clusters were defined as the regions of interest (ROIs), and the regional mean $\mathrm{GABA}_{\mathrm{A}}$ receptor binding potentials of each subject were calculated based on the ROIs using the individual $\mathrm{GABA}_{\mathrm{A}}$ receptor binding potential maps. Group comparisons of the ROI values between the aripiprazole and risperidone groups, between the aripiprazole and control groups or between the risperidone and control groups were performed using independent t-tests. Scheffés method was applied to correct for multiple comparisons. Significance level for post hoc analyses was set at $\mathrm{p}<0.05$. Nvox: number of voxels, Zmax: maximum Z value, MNI: Montreal Neurological Institute, BA: Brodmann area

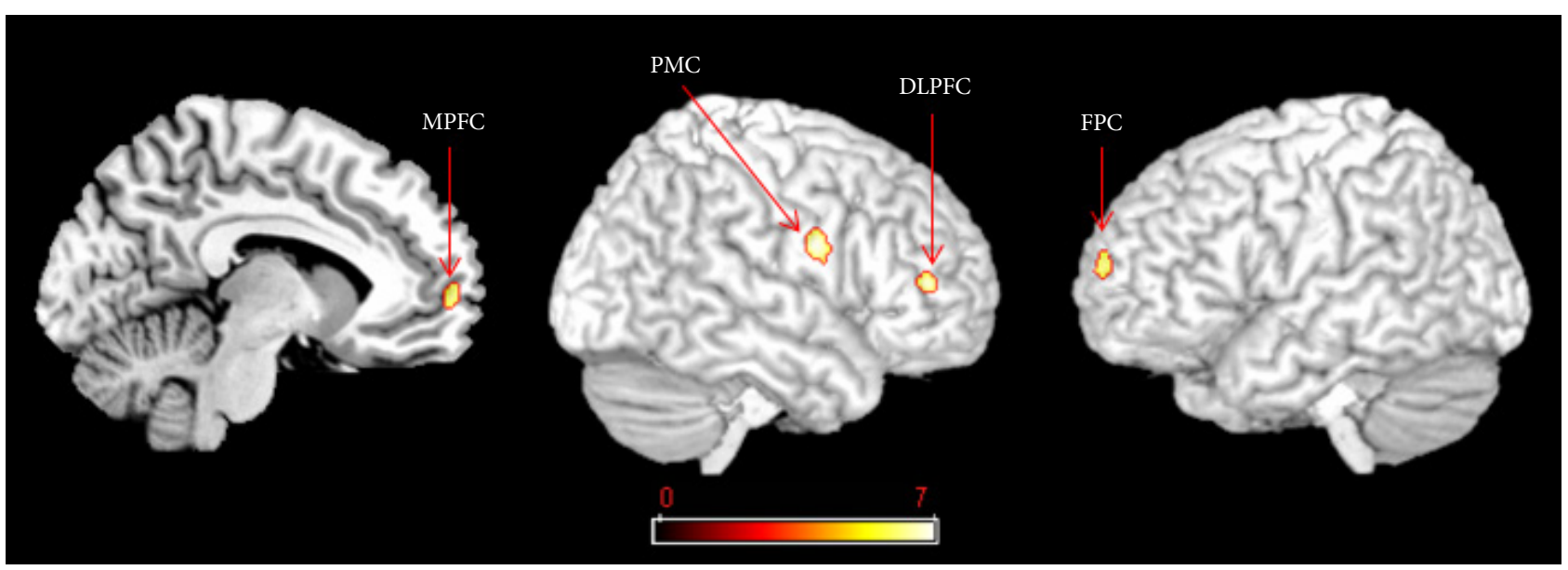

Figure 1. $G A B A_{A}$ receptor binding potentials in the right medial prefrontal cortex (MPFC), the left frontopolar cortex (FPC), the right dorsolateral prefrontal cortex (DLPFC) and the premotor cortex (PMC) were significantly lower in the aripiprazole group than the risperidone group [family wise error (FWE) corrected $p<0.05]$. 
for a long time, our findings of regional differences of GAB$A_{A}$ receptor binding potential might also reflect an effect of medication or deterioration after long duration of illness.

In a comparison among the three groups, the aripiprazole group showed significantly decreased $\left[{ }^{18} \mathrm{~F}\right]$-FFMZ binding potentials in the right MPFC, left FPC and right DLPFC compared to the risperidone group, suggesting increased prefrontal GABA transmission due to aripiprazole. Since appropriate GABAergic inhibition in the prefrontal cortex is essential for information processing ${ }^{20}$ increased prefrontal GABA transmission can be interpreted as increased functional activity. The MPFC is one of the principal components of social brain, ${ }^{10,11}$ brain regions specialized for social cognition. The MPFC integrates social information across time, allows reflection and representation of traits and norms ${ }^{21}$ and is also involved in theory of mind and mentalizing. ${ }^{11}$ The FPC acts as a modulator of social cognition by overriding ongoing processing to explore new options..$^{22}$ In addition, the DLPFC is thought to contribute to cognitive control in social situations by maintaining understanding of one person's intentions and evaluating whether a second person's actions appear consistent with those intentions. ${ }^{23}$ Collectively, the effect of increased prefrontal GABA transmission may have possible contribution to aripiprazole's social competence improvement.

Both the aripiprazole and risperidone groups showed no significant difference in $\left[{ }^{18} \mathrm{~F}\right]$-FFMZ binding potentials in the right MPFC and right DLPFC compared to the control group. The functional and structural abnormalities in the MPFC and DLPFC have been consistently reported in patients with schizophrenia. ${ }^{24,25}$ Moreover, recent studies found elevated GABA levels in the MPFC in unmedicated patient ${ }^{26}$ and altered GA$\mathrm{BA}$ receptor subunit in the DLPFC in patients regardless of medication use. ${ }^{27}$ Comparable levels of $\mathrm{GABA}_{\mathrm{A}}$ receptor binding potentials in the MPFC and DLPFC suggest that aripiprazole and risperidone administration may possibly normalize GABA alterations in patients with schizophrenia. However, future studies with drug naïve patients using $\left[{ }^{18} \mathrm{~F}\right]$-FFMZ PET should be warranted because comparable levels of $\mathrm{GABA}_{\mathrm{A}}$ receptor binding potentials might be due to decreased sensitivity of $\left[{ }^{18} \mathrm{~F}\right]$-FFMZ PET imaging.

Compared to both the risperidone and control groups, the aripiprazole group showed decreased $\left[{ }^{18} \mathrm{~F}\right]$-FFMZ binding potential in the right premotor cortex, which indicates increases in GABA transmission in the premotor area by aripiprazole. Because GABA inhibits the function of the premotor cortex ${ }^{28}$ this finding of increased premotor GABA transmission in the aripiprazole group suggests decreased premotor functioning. The premotor cortex forms the core of the mirrorneuron system which estimates the mental state of the other person in a social interaction ${ }^{11}$ and decreased premotor fun- ctioning could be opposite of our hypothesis. However, patients with Parkinson's disease show increased activity in the premotor cortex compared to healthy controls, ${ }^{29}$ and this hyperactivation in the premotor cortex decreases after pharmacologic treatment. ${ }^{30}$ Therefore, decreased premotor functioning may be related to less liability for neuroleptic induced parkinsonism found in aripiprazole compared with risperidone. ${ }^{5}$ Since social functioning can be negatively influenced by parkinsonism, ${ }^{31}$ decreased premotor activity may be also possibly linked to social competence improvement by aripiprazole. But it is hard to interpret that the aripiprazole group had decreased premotor functioning compared to the control group. Decreased premotor functioning may be a compensatory mechanism for antipsychotic induced parkinsonian symptoms; however, future controlled studies are needed.

The present study has several limitations, most of which stemmed from an open, naturalistic design of the present study in an outpatient clinic for chronic patients. First, there was a risk of selection bias because the medication groups were not randomly assigned. Second, the sample size of each group was small. Third, the gender ratio in the aripiprazole and risperidone groups was not matched. Fourth, measures of social competence, parkinsonian symptoms and smoking history were not administered. Most of all, we used brain areas instead of behavioral measures about social competence to explain the relationship between aripiprazole administration and social competence improvement. Therefore, future randomized controlled studies including extensive measures are needed for more precise conclusions about the relation between medication and behavioral functioning.

In conclusion, administration of aripiprazole resulted in changes in prefrontal GABA transmission, including increases in the MPFC, FPC, DLPFC and premotor regions. In that these regions have been reported to be involved in various social functions, social competence improvement would be one of the possible reasons for $\mathrm{GABA}_{\mathrm{A}}$ receptor changes. Despite limitations, our preliminary study contributes meaningful data as to how the GABA system may be associated with clinical advantages of aripiprazole.

\section{Acknowledgments}

This study was supported by a 2008 faculty research grant from Yonsei University College of Medicine [6-2008-0238].

\section{REFERENCES}

1. Kerwin R, Millet B, Herman E, Banki CM, Lublin H, Pans M, et al. A multicentre, randomized, naturalistic, open-label study between aripiprazole and standard of care in the management of community-treated schizophrenic patients Schizophrenia Trial of Aripiprazole: (STAR) study. Eur Psychiatry 2007;22:433-443.

2. Mizrahi R, Mamo D, Rusjan P, Graff A, Houle S, Kapur S. The relationship between subjective well-being and dopamine D2 receptors in 
patients treated with a dopamine partial agonist and full antagonist antipsychotics. Int J Neuropsychopharmacol 2009;12:715-721.

3. Park KM, Ku J, Park IH, Park JY, Kim SI, Kim JJ. Improvement in social competence in patients with schizophrenia: a pilot study using a performance-based measure using virtual reality. Hum Psychopharmacol 2009;24:619-627.

4. Liberman RP, Mueser KT, Wallace CJ, Jacobs HE, Eckman T, Massel HK. Training skills in the psychiatrically disabled: learning coping and competence. Schizophr Bull 1986;12:631-647.

5. Chan HY, Lin WW, Lin SK, Hwang TJ, Su TP, Chiang SC, et al. Efficacy and safety of aripiprazole in the acute treatment of schizophrenia in Chinese patients with risperidone as an active control: a randomized trial. J Clin Psychiatry 2007;68:29-36.

6. Livingston MG. Risperidone. Lancet 1994;343:457-460.

7. Vinkers CH, Mirza NR, Olivier B, Kahn RS. The inhibitory GABA system as a therapeutic target for cognitive symptoms in schizophrenia: investigational agents in the pipeline. Expert Opin Investig Drugs 2010;19:1217-1233.

8. Choe BY, Kim KT, Suh TS, Lee C, Paik IH, Bahk YW, et al. 1H magnetic resonance spectroscopy characterization of neuronal dysfunction in drug-naive, chronic schizophrenia. Acad Radiol 1994;1:211-216.

9. Tayoshi S, Nakataki M, Sumitani S, Taniguchi K, Shibuya-Tayoshi S, Numata $S$, et al. GABA concentration in schizophrenia patients and the effects of antipsychotic medication: a proton magnetic resonance spectroscopy study. Schizophr Res 2010;117:83-91.

10. Adolphs R. The social brain: neural basis of social knowledge. Annu Rev Psychol 2009;60:693-716.

11. Frith CD. The social brain? Philos Trans R Soc Lond B Biol Sci 2007;362: 671-678.

12. Gallese V. Before and below 'theory of mind': embodied simulation and the neural correlates of social cognition. Philos Trans R Soc Lond B Biol Sci 2007;362:659-669.

13. First MB, Gibbon M, Spitzer RL, Williams JBW. Structured Clinical Interview for DSM-IV Axis I Disorders. New York: New York State Psychiatric Institute Biometric Research; 1996.

14. Kay SR, Fiszbein A, Opler LA. The positive and negative syndrome scale (PANSS) for schizophrenia. Schizophr Bull 1987;13:261-276.

15. Lee JD, Park HJ, Park ES, Kim DG, Rha DW, Kim EY, et al. Assessment of regional GABA(A) receptor binding using 18F-fluoroflumazenil positron emission tomography in spastic type cerebral palsy. Neuroimage 2007;34:19-25.

16. Millet P, Graf C, Buck A, Walder B, Ibanez V. Evaluation of the reference tissue models for PET and SPECT benzodiazepine binding parameters. Neuroimage 2002;17:928-942.

17. Nichols T, Hayasaka S. Controlling the familywise error rate in functional neuroimaging: a comparative review. Stat Methods Med Res
2003;12:419-446.

18. Drevets WC, Savitz J, Trimble M. The subgenual anterior cingulate cortex in mood disorders. CNS Spectr 2008;13:663-681.

19. Olson IR, Plotzker A, Ezzyat Y. The Enigmatic temporal pole: a review of findings on social and emotional processing. Brain 2007;130:1718-1731.

20. Constantinidis C, Williams GV, Goldman-Rakic PS. A role for inhibition in shaping the temporal flow of information in prefrontal cortex. Nat Neurosci 2002;5:175-180.

21. Van Overwalle F. Social cognition and the brain: a meta-analysis. Hum Brain Mapp 2009;30:829-858.

22. Daw ND, O’Doherty JP, Dayan P, Seymour B, Dolan RJ. Cortical substrates for exploratory decisions in humans. Nature 2006;441:876-879.

23. Weissman DH, Perkins AS, Woldorff MG. Cognitive control in social situations: a role for the dorsolateral prefrontal cortex. Neuroimage 2008; 40:955-962.

24. Chai XJ, Whitfield-Gabrieli S, Shinn AK, Gabrieli JD, Nieto Castanon A, McCarthy JM, et al. Abnormal medial prefrontal cortex restingstate connectivity in bipolar disorder and schizophrenia. Neuropsychopharmacology 2011;36:2009-2017.

25. Pomarol-Clotet E, Canales-Rodriguez EJ, Salvador R, Sarro S, Gomar JJ, Vila F, et al. Medial prefrontal cortex pathology in schizophrenia as revealed by convergent findings from multimodal imaging. Mol Psychiatry 2010;15:823-830.

26. Kegeles LS, Mao X, Stanford AD, Girgis R, Ojeil N, Xu X, et al. Elevated prefrontal cortex gamma-aminobutyric acid and glutamate-glutamine levels in schizophrenia measured in vivo with proton magnetic resonance spectroscopy. Arch Gen Psychiatry 2012;69:449-459.

27. Maldonado-Aviles JG, Curley AA, Hashimoto T, Morrow AL, Ramsey AJ, O'Donnell P, et al. Altered markers of tonic inhibition in the dorsolateral prefrontal cortex of subjects with schizophrenia. Am J Psychiatry 2009;166:450-459.

28. Sawaguchi T, Yamane I, Kubota K. Application of the GABA antagonist bicuculline to the premotor cortex reduces the ability to withhold reaching movements by well-trained monkeys in visually guided reaching task. J Neurophysiol 1996;75:2150-2156.

29. Yu H, Sternad D, Corcos DM, Vaillancourt DE. Role of hyperactive cerebellum and motor cortex in Parkinson's disease. Neuroimage 2007; 35:222-233.

30. Peters S, Suchan B, Rusin J, Daum I, Koster O, Przuntek H, et al. Apomorphine reduces BOLD signal in fMRI during voluntary movement in Parkinsonian patients. Neuroreport 2003;14:809-812.

31. Bozikas VP, Kosmidis MH, Kafantari A, Gamvrula K, Vasiliadou E, Petrikis $P$, et al. Community dysfunction in schizophrenia: rate-limiting factors. Prog Neuropsychopharmacol Biol Psychiatry 2006;30:463470 . 